\title{
A biomechanical comparison of 3 different posterior fixation techniques for 2-level lumbar spinal disorders
}

\author{
*Fubing Liu, MD,' Zhenzhou Feng, MD, PhD, ${ }^{1}$ Tianze Liu, MD," Qinming Fei, MD, PhD, ${ }^{1}$ \\ Chun Jiang, MD, PhD, ${ }^{1}$ Yuanchao Li, PhD, ${ }^{2}$ Xiaoxing Jiang, MD, PhD, ${ }^{1}$ and Jian Dong, MD, PhD ${ }^{1}$ \\ 'Department of Orthopaedics, Zhongshan Hospital of Fudan University; and 2Institute of Biomedical Production and Life Quality \\ Program, Shanghai Jiao Tong University, Shanghai, China
}

\begin{abstract}
OBJECT This study sought to make a biomechanical comparison of 3 different posterior fixation techniques for 2-level lumbar spinal disorders.

METHODS Eight fresh-frozen human cadaver lumbar spines (4 from L-1 to L-5, 4 from L-1 to S-1) were tested by applying pure moments of $\pm 8 \mathrm{Nm}$. Each specimen was first tested intact, and then the left facetectomies of $L 3-4$ and $L 4-5$ were performed to establish an unstable condition without removal of discs. Three instrumentation systems were then tested randomly: unilateral pedicle screw (UPS), UPS with contralateral translaminar facet screw (UPSFS), and bilateral pedicle screw (BPS). The range of motion (ROM) and the neutral zone (NZ) of L3-5 were measured.
\end{abstract}

RESULTS All fixation types could reduce the ROM of $L 3-5$ significantly in flexion, extension, and lateral bending, compared with the intact state. In axial torsion, only BPS reduced the ROM significantly, compared with the intact state. The UPSFS technique provided intermediate stability, which was superior to the UPS in flexion-extension and lateral bending, and inferior to the BPS in lateral bending. Compared with the intact state, the NZs decreased significantly for UPS, UPSFS, and BPS in flexion-extension, while not significantly in lateral bending and axial torsion.

CONCLUSIONS In this study, among the 3 fixation techniques, BPS offered the highest stability, UPSFS provided intermediate stability, and UPS was the least stable for 2-level lumbar spinal disorders. UPSFS appeared to be able to offer a less invasive choice than BPS in well-selected patients with 2-level lumbar spinal disorders.

http://thejns.org/doi/abs/10.3171/2015.7.SPINE1534

KEY WORDS biomechanical; posterior; fixation; 2-level; lumbar spinal disorders

$\mathrm{L}$ UMBAR spinal instrumentation is a commonly performed surgical procedure, which is indicated for a variety of lumbar pathologies such as degenerative disease, trauma, tumor, and deformities. The main reason for the application of internal instrumentation is that it plays an essential role in establishing a mechanically stable environment to promote the formation of a fusion mass. There are various posterior fixation techniques used to assist in spinal fusion, among which the bilateral pedicle screw (BPS) technique is deemed to be the "gold standard" of instrumentation, providing rigid fixation and high fusion rates. ${ }^{25}$ However, BPS fixation has some drawbacks as well, including a requirement for excessive paraspinal muscle dissection and retraction during instrumentation, as well as increased time and expense..$^{2,9,19,22}$ Recently, uni- lateral pedicle screw (UPS) fixation has come into use for its reduced invasiveness, acquired good clinical outcome, and satisfying fusion rate, $, 5,26,27$ while biomechanical studies have revealed that, compared with bilateral fixation, UPS fixation allowed significant off-axis rotation, potentially detrimental to stability..$^{10,12,25}$ To preserve the reduced invasiveness of UPS fixation and overcome the shortcomings of insufficient strength, a hybrid fixation of UPS with a contralateral translaminar facet screw (UPSFS) has been applied in lumbar spinal surgeries. ${ }^{15,23}$ To the best of our knowledge, several studies have evaluated the biomechanical performance of this hybrid instrumentation technique. ${ }^{15,23-25}$ However, most researchers only focused on single-level conditions, and the biomechanics of this hybrid technique at 2 levels have not been well characterized.

ABBREVIATIONS BPS = bilateral pedicle screw; NZ = neutral zone; ROM = range of motion; TLFS = translaminar facet screw; UPS = unilateral pedicle screw; UPSFS = UPS with contralateral translaminar facet screw.

SUBMITTED January 9, 2015. ACCEPTED July 16, 2015

INCLUDE WHEN CITING Published online December 4, 2015; DOI: 10.3171/2015.7.SPINE1534.

* Drs. F. Liu, Feng, and T. Liu contributed equally to this work. Drs. X. Jiang and Dong share senior authorship of this work. 
As the anatomy and biomechanics of 2-level lumbar spine disorders differ from those of 1-level disorders, it is better to investigate the biomechanical performance of these fixation techniques in 2-level conditions instead of simply extrapolating those in 1-level conditions. Therefore, the purpose of the current study was to make a biomechanical comparison of 3 different posterior fixation techniquesUPS, UPSFS, and BPS fixation - for 2-level lumbar spinal disorders. In addition, as the main scope of our study was to compare different fixation techniques, the discs of L3-4 and L4-5 were kept intact and cage-related fusions were not performed, to rule out the cages' extra stabilization effect on spinal motion segments. Although fixation without cage-related fusion is slightly different from clinical practice, it can make the comparisons more direct and not affected by cage-related factors.

\section{Methods \\ Specimen Preparation}

As 2-level lumbar spinal pathologies often involve L3-5 or L4-S1 clinically, we selected L3-5 as the object of study. Eight fresh-frozen human cadaver lumbar spines (4 from L-1 to L-5, 4 from L-1 to S-1) were obtained from the Human Anatomy Department of our University, including 3 female and 5 male specimens. The mean age of these cadavers was $44.5 \pm 11.4$ years old, ranging from 25 to 60 years of age. All spines were stored at $-80^{\circ} \mathrm{C}$ and then thawed at room temperature $\left(20^{\circ} \mathrm{C}\right)$ overnight the day before testing. They were inspected carefully and radiographed anteroposteriorly and laterally to exclude fractures, osteoporosis, deformities, and any metastatic disease. The paraspinal musculature was denuded, with care taken to preserve the joint capsules, supra- and interspinous ligaments, ligamenta flava, and discs. Each spine was potted proximally at L-1 and distally at L-5 (for L1 -5 specimens) or S-1 (for L1-S1 specimens) in customized gripping fixtures using a denture base resin. Before potting, industrial drywall screws were placed in the end of the upper and lower vertebrae of each specimen in a multiplanar fashion to provide anchorage in the potting material. Half of the caudal and cranial vertebral body was embedded, leaving the discs and facet joints free of embedding and accessible for the application of instrumentation.

\section{Testing Protocol}

Once potted, the spines were mounted vertically in a commercial spine simulator, MTS 858 mini-bionix II (MTS), a servohydraulic biaxial test frame that could provide force and position control in 6 degrees of freedom: flexion/extension, left/right lateral bending, and left/right torsion (Fig. 1). Axial compressive preload was not applied when testing, and the moment for each testing direction was selected as $8.0 \mathrm{Nm}$ at a loading rate of $1 \%$ second. Angle displacement of the vertebral bodies during testing was tracked by an Optotrak Certus (NDI, Inc.) motion analysis system, which used infrared light-emitting diode markers, rigidly attached to each vertebral body. An inline personal computer calculated positional changes, measuring displacement with an accuracy of $0.1^{\circ}$ in all planes. Each mode of loading was applied to the specimen

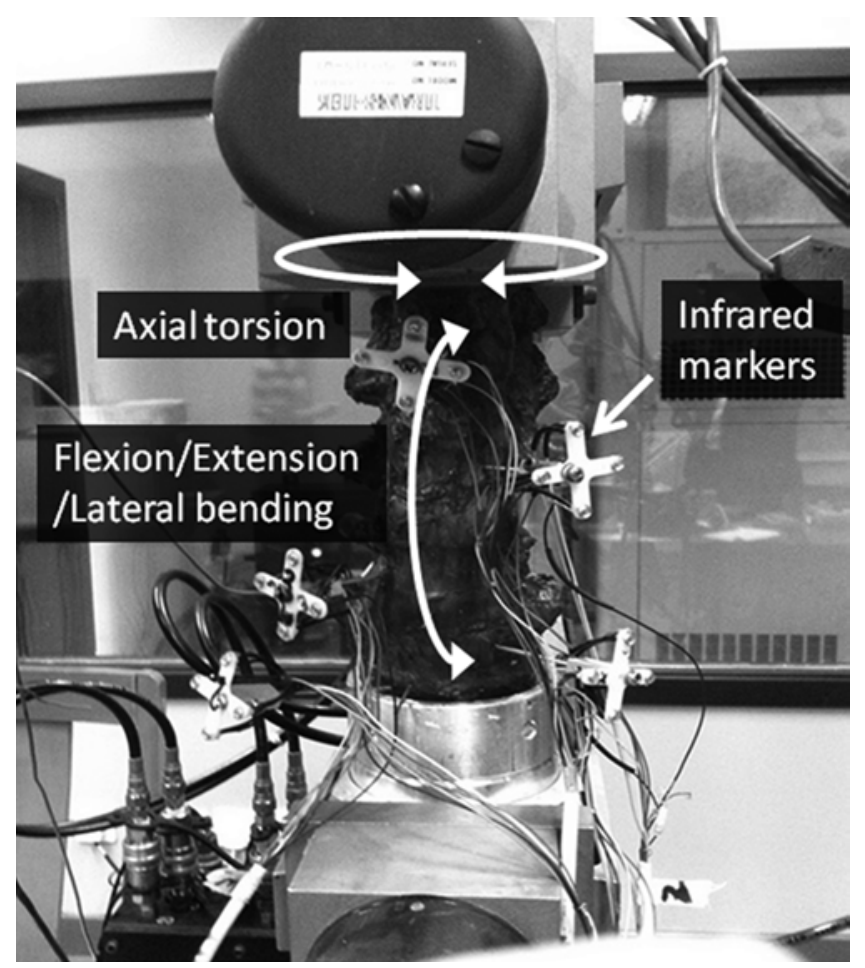

FIG. 1. Photograph of the spine simulator with different modes of applied motion.

3 times and only the data obtained for the third time were recorded so as to stabilize the viscoelastic effect. Between testing modes, there was a 60 -second unloaded recovery period to reduce the effect of testing order on the specimen responses. During testing, specimens were kept moist by periodic sprays of $0.9 \%$ saline solution.

Each specimen was first tested intact and then left facetectomies of L3-4 and L4-5 were performed to establish an unstable condition. Three instrumentation systems yielded 6 kinds of testing orders. To minimize the variance of biomechanical performance induced by different testing orders, as previous studies did, ${ }^{24,25}$ the following testing order of each instrumentation system (UPS, UPSFS, and BPS; Fig. 2) was generated by a series of random numbers (Table 1). In our test, polyaxial pedicle screws (DePuy Spine), $6.0 \mathrm{~mm}$ in diameter and $45 \mathrm{~mm}$ in length, were used at the L3-5 level and connected by $5.5-\mathrm{mm}-$ diameter rods. The translaminar facet screw (TLFS) was a 4.5-mm diameter, 45-mm-long cannulated screw (Synthes) and was inserted using the Magerl technique. ${ }^{21}$

\section{Data Collection and Analysis}

For the implanted levels, both the range of motion (ROM) and neutral zone (NZ) of the techniques were measured. The ROM was defined as the angular excursion in all directions at maximum load; the NZ was defined as the difference at zero load between the angular positions in all directions of the loading and unloading phases. ${ }^{19,24}$

Statistical analysis was performed using SPSS (version 19.0 for Windows, SPSS Inc.). For the ROM and NZ data, single-factor ANOVA with repeated measures was per- 


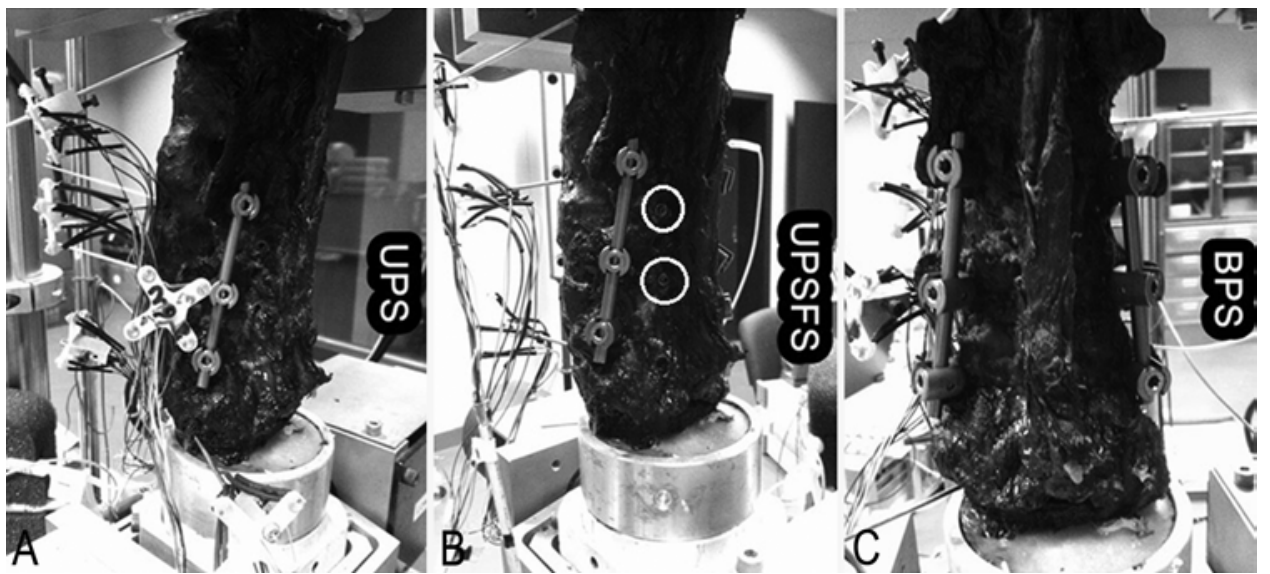

FIG. 2. Photographs of 3 different fixation types in vitro, with 2 white circles indicating the TLFSs.

formed. Tukey's post hoc test was used to compare different instrumentation configurations. Normalization to the intact spine was performed using the following formula: mean ROM of certain instrumented condition/the counterpart of the intact situation $\times 100 \%$. Statistical significance was set at a probability value less than 0.05 .

\section{Results}

ROMs and NZs in each loading mode for each specimen were recorded and compared with the intact state (Tables 2 and 3, Fig. 3).

\section{Flexion-Extension}

All instrumentation techniques significantly reduced the ROM of the L3-5 segment compared with the intact state $\left(12.52^{\circ} \pm 2.80^{\circ} ; \mathrm{p}<0.05\right)$ in flexion-extension. The UPS $\left(7.15^{\circ} \pm 1.19^{\circ}\right)$, UPSFS $\left(4.46^{\circ} \pm 1.77^{\circ}\right)$, and BPS $\left(3.65^{\circ} \pm 1.41^{\circ}\right)$ fixation decreased the ROM $\left(12.52^{\circ}\right.$ $\pm 2.80^{\circ}$ ) by $42.9 \%, 64.4 \%$, and $70.8 \%$, respectively. The UPSFS and BPS groups also decreased the ROM significantly $(p<0.05)$ compared with the UPS group, while no significant difference existed between the UPSFS and BPS groups. Regarding the NZ in flexion-extension, UPS $\left(2.04^{\circ} \pm 0.77^{\circ}\right)$, UPSFS $\left(0.98^{\circ} \pm 0.72^{\circ}\right)$, and BPS $\left(0.61^{\circ} \pm\right.$ $0.78^{\circ}$ ) fixation significantly reduced by $41.0 \%, 71.7 \%$, and $82.4 \%(\mathrm{p}<0.05)$, respectively, compared with the intact spine $\left(3.46^{\circ} \pm 1.51^{\circ}\right)$.

\section{Lateral Bending}

A similar trend was observed in lateral bending as was noted in flexion-extension. All fixation modes decreased the ROM of the L3-5 segment significantly compared with the intact state $\left(15.58^{\circ} \pm 3.94^{\circ} ; \mathrm{p}<0.05\right)$. The UPS $\left(9.80^{\circ} \pm 2.03^{\circ}\right)$, UPSFS $\left(6.40^{\circ} \pm 2.86^{\circ}\right)$, and BPS $\left(2.94^{\circ} \pm\right.$ $1.85^{\circ}$ ) decreased the ROM by $37.1 \%, 58.9 \%$, and $81.1 \%$, respectively. The UPSFS and BPS groups also decreased the ROM significantly compared with the UPS group $(\mathrm{p}<$ 0.05 ), and there was also a significant difference between the UPSFS and BPS techniques $(\mathrm{p}<0.05)$. Regarding the NZ data, the UPS $\left(1.50^{\circ} \pm 1.10^{\circ}\right)$, UPSFS $\left(0.94^{\circ} \pm 0.62^{\circ}\right)$, and BPS $\left(0.31^{\circ} \pm 0.37^{\circ}\right)$ fixation techniques reduced sig- nificantly by $31.5 \%, 57.1 \%$, and $85.8 \%(\mathrm{p}<0.05)$ in lateral bending, respectively, compared with the intact spine $\left(2.19^{\circ} \pm 0.88^{\circ}\right)$.

\section{Axial Torsion}

The UPS $\left(4.41^{\circ} \pm 1.06^{\circ}\right)$, UPSFS $\left(3.78^{\circ} \pm 1.45^{\circ}\right)$, and BPS $\left(3.07^{\circ} \pm 1.33^{\circ}\right)$ techniques decreased the ROM in axial torsion by $10.5 \%, 23.3 \%$, and $37.7 \%$, respectively, and only the BPS exhibited a significant difference compared with the intact state $\left(4.93^{\circ} \pm 1.12^{\circ} ; \mathrm{p}<0.05\right)$. Only the BPS group decreased the ROM significantly compared with the UPS group $(p<0.05)$. There was no significant difference between the UPSFS and BPS groups. For the NZ data, the UPS $\left(0.54^{\circ} \pm 0.23^{\circ}\right)$ and UPSFS $\left(0.50^{\circ} \pm 0.32^{\circ}\right)$ techniques nonsignificantly $(\mathrm{p}>0.05)$ reduced the NZ by $20.6 \%$ and $26.5 \%$, respectively, and the BPS $\left(0.33^{\circ} \pm 0.30^{\circ}\right)$ technique reduced the NZ by $51.5 \%$, a significant difference $(\mathrm{p}<$ $0.05)$ compared with the intact spine $\left(0.68^{\circ} \pm 0.15^{\circ}\right)$.

\section{Discussion}

Various posterior fixation techniques have been applied in lumbar spinal disorders, aiming to establish a mechanically stable environment to promote the formation of a fusion mass. Recently, a new instrumentation type, UPSFS, has gradually attracted the attention of spine surgeons, for its reduced invasiveness and adequate fixation strength. ${ }^{15,23}$

TABLE 1. Demographic data and testing order of specimens

\begin{tabular}{ccc}
\hline Case No. & Age (yrs), Sex & Testing Order \\
\hline 1 & $25, \mathrm{M}$ & UPS, BPS, UPSFS \\
\hline 2 & $34, \mathrm{M}$ & BPS, UPS, UPSFS \\
\hline 3 & $60, \mathrm{~F}$ & UPS, UPSFS, BPS \\
\hline 4 & $40, \mathrm{~F}$ & UPSFS, BPS, UPS \\
\hline 5 & $56, \mathrm{M}$ & BPS, UPSFS, UPS \\
\hline 6 & $45, \mathrm{M}$ & UPS, UPSFS, BPS \\
\hline 7 & $50, \mathrm{~F}$ & UPSFS, UPS, BPS \\
\hline 8 & $46, \mathrm{M}$ & BPS, UPSFS, UPS \\
\hline
\end{tabular}


TABLE 2. ROM of $L 3-5$ during various loading modes*

\begin{tabular}{lcccc}
\hline Loading Modes & Intact $\left(^{\circ}\right)$ & UPS $\left(^{\circ}\right)$ & UPSFS $\left(^{\circ}\right)$ & BPS $\left(^{\circ}\right)$ \\
\hline Flexion & $7.13 \pm 1.18 \ddagger$ & $4.01 \pm 0.92 \dagger$ & $2.76 \pm 1.10 \dagger \ddagger$ & $1.75 \pm 0.75 \dagger \ddagger$ \\
\hline Extension & $5.38 \pm 1.88 \ddagger$ & $3.14 \pm 0.38 \dagger$ & $1.71 \pm 0.78 \dagger \ddagger$ & $1.91 \pm 1.03 \dagger \ddagger$ \\
\hline Flexion-extension & $12.52 \pm 2.80 \ddagger$ & $7.15 \pm 1.19 \dagger$ & $4.46 \pm 1.77 \dagger \ddagger$ & $3.65 \pm 1.41 \dagger \ddagger$ \\
\hline Lt bending & $7.89 \pm 1.66 \ddagger$ & $5.07 \pm 1.15 \dagger$ & $3.54 \pm 1.59 \dagger \ddagger$ & $1.54 \pm 0.93 \dagger \ddagger$ \\
\hline Rt bending & $7.70 \pm 2.39 \ddagger$ & $4.72 \pm 0.92 \dagger$ & $2.86 \pm 1.31 \dagger \ddagger$ & $1.40 \pm 0.93 \dagger \ddagger$ \\
\hline Lateral bending & $15.58 \pm 3.94 \ddagger$ & $9.80 \pm 2.03 \dagger$ & $6.40 \pm 2.86 \dagger \ddagger$ & $2.94 \pm 1.85 \dagger \ddagger$ \\
\hline Lt torsion & $2.53 \pm 0.57$ & $2.00 \pm 0.50$ & $1.84 \pm 0.42 \dagger$ & $1.57 \pm 0.69 \dagger$ \\
\hline Rt torsion & $2.40 \pm 0.58$ & $2.41 \pm 0.63$ & $2.07 \pm 1.04$ & $1.50 \pm 0.64 \dagger \ddagger$ \\
\hline Axial torsion & $4.93 \pm 1.12$ & $4.41 \pm 1.06$ & $3.78 \pm 1.45$ & $3.07 \pm 1.33 \dagger \ddagger$ \\
\hline
\end{tabular}

* All data given as mean \pm SD.

$\dagger$ Represents a significant difference from the intact state $(p<0.05)$.

$\ddagger$ Represents a significant difference from the UPS technique $(p<0.05)$.

In an in vitro study, Slucky et al. ${ }^{25}$ tested 7 fresh-frozen human cadaveric specimens using $\pm 5.0-\mathrm{Nm}$ torques and $50-\mathrm{N}$ axial compressive loads. They found that no measurable differences in terms of the stiffness or ROM between BPSs and UPSFSs were observed during flexion-extension, lateral bending, and axial rotation after transforaminal lumbar interbody fusion. In another biomechanical study, Sethi et al. ${ }^{24}$ tested 7 fresh human lumbar spines (L2-5) by applying pure moments of $\pm 8 \mathrm{Nm}$, with no compressive preload, and found that UPSFS fixation was able to achieve more reduction in ROM compared with UPS fixation and was comparable to BPS fixation in flexion-extension, lateral bending, and axial torsion. However, both of these studies only focused on single-level lumbar spinal fusion (L3-4), and whether UPSFS fixation could be extended to 2-level or even multilevel conditions remains unclear. Therefore, we performed the current study to investigate the biomechanics of this technique in 2-level lumbar spinal modes.

In our study, the situation differs from the single-level condition. Among all these 3 fixation techniques, UPS remains the least stable, but UPSFS is no more equivalent to BPS as the ROM of UPSFS is higher than BPS in lateral bending. This is evidenced by another study in which Fan et al. ${ }^{7}$ demonstrated that the mechanical performance of 2-level bilateral TLFS fixation was significantly inferior to that of the BPS in lateral bending because the locked facets eliminated rotations in flexion-extension and axial rotation, but were less effective in lateral bending. Actually, the UPSFS technique in our study is composed of 2 parts, the UPS and the contralateral TLFS. The addition of the TLFS to the UPS confers to it intermediate stability, superior to the UPS and inferior to the BPS in stability. However, this is different from what Gong et al. ${ }^{11}$ demonstrated in a finite element model, in which they revealed that UPSFS fixation was superior to either UPS or BPS fixation in improving stability and reducing stress biomechanically. The reason for this discrepancy might be explained by the variances of these two study methods. Although these two are both in vitro studies, cadaveric study might be more close to the in vivo condition than the finite element model.

UPS has gradually been favored by some surgeons in recent years as it could reduce the extent of tissue injury and allow for less surgical time and blood loss, less postoperative pain, and early recovery and rehabilitation of the patient. ${ }^{3,4,17,18}$ However, previous studies have revealed that the unilateral technique might not have sufficient stability and would lead to considerable off-axis rotational motion. ${ }^{10,12}$ Additionally, UPS may result in increased rates of cage migration and scoliosis. ${ }^{1,6,13}$ In the current study, compared with the intact spine, UPS is more stable in flexion-extension and lateral bending, and as stable in axial torsion. Contrary to the study by Harris et al..$^{12}$ but consistent with the studies by Slucky et al..$^{25}$ and Sethi et al.., the off-axis movement never occurred. In the study by Harris et al., they used elderly specimens (average age 81 years) with age-appropriate osteoporosis and the transforaminal lumbar interbody fusion procedure had a severe impact on rotational stability; none of the stabilization methods were able to restore stability under axial rotation loads. In our study and the other two studies, younger cadavers who had

TABLE 3. NZs of L3-5 during various loading modes*

\begin{tabular}{|c|c|c|c|c|}
\hline Loading Modes & $\operatorname{lntact}\left({ }^{\circ}\right)$ & $\operatorname{UPS}\left({ }^{\circ}\right)$ & UPSFS $\left({ }^{\circ}\right)$ & $\operatorname{BPS}\left({ }^{\circ}\right)$ \\
\hline Flexion-extension & $3.46 \pm 1.51 \ddagger$ & $2.04 \pm 0.77 \dagger$ & $0.98 \pm 0.72 \dagger \ddagger$ & $0.61 \pm 0.78 \dagger \ddagger$ \\
\hline Lateral bending & $2.19 \pm 0.88$ & $1.50 \pm 1.10$ & $0.94 \pm 0.62 \dagger$ & $0.31 \pm 0.37 \dagger \ddagger$ \\
\hline Axial torsion & $0.68 \pm 0.15$ & $0.54 \pm 0.23$ & $0.50 \pm 0.32$ & $0.33 \pm 0.30 \dagger$ \\
\hline
\end{tabular}




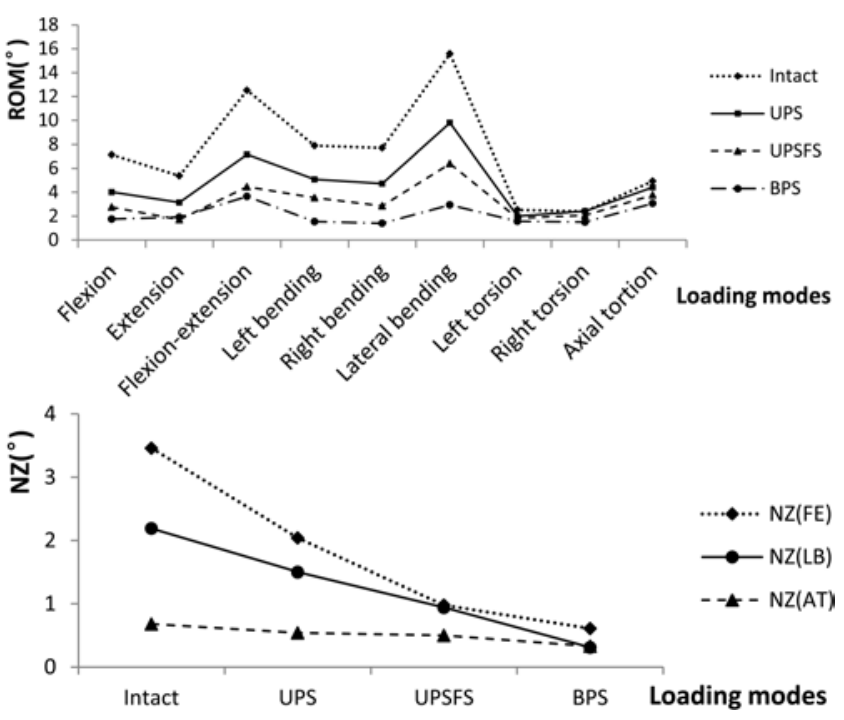

FIG. 3. Graphs showing the mean ROMs (upper) and NZs (lower) of L3 -5 during various loading modes. AT = axial torsion; FE = flexionextension; LB = lateral bending.

better bone quality were used. In addition, the contralateral facet joints were preserved, which theoretically might also be involved in eliminating the off-axis movement. However, like the conditions in 1-level lumbar spine disorders, UPS remains the least biomechanically stable, which reminds us that the clinical application of UPS in 2-level lumbar spinal disorders should be prudently selected.

The UPSFS technique provides intermediate stability. As a part of UPSFS, the TLFS, first used by Magerl in $1984,{ }^{21}$ is inserted from the base of the spinous process, then traverses the contralateral lamina and facet joint, and ends at the base of the transverse process, thereby stiffening and immobilizing the spinal segments. Apparently, the stability of UPSFS is imparted by both the UPS and the contralateral TLFS, which is comparable to BPS, considered the "gold standard" in flexion-extension and axial torsion, but is inferior in lateral bending. However, as the main movements of the lumbar spine are flexionextension and axial torsion in our daily lives, especially flexion-extension, a slight inferiority in lateral bending of UPSFS fixation is not believed to affect the entire stability. UPSFS could afford adequate stability in 2-level lumbar spinal disorders for most patients, except in some special groups who greatly rely on lateral bending of the spine, such as dancers and athletes. More importantly, the TLFS of UPSFS could be inserted in the same approach as the pedicle screws ${ }^{20}$ or could be inserted using a percutaneous method ${ }^{14,16,28}$ in clinical practice, which could reduce the soft-tissue dissections and allow for less surgical time, blood loss, and implant cost.

There are several drawbacks in the current study. First, this was an in vitro spinal biomechanical test, which has inherent limitations, such as exclusions of the effect of muscles, weight of the torso above the instrumented level, and complex movements occurring in vivo. The discs were kept intact and the cage-applied fusions were not performed, as the cage-related factors such as cage sizes and positions would additionally influence the stability of spinal motion segments. Although our method may not ideally represent the most common clinical scenario, it can make the comparisons between fixation techniques more direct and unaffected by other factors. The clinical implication is that we can make a better decision regarding fusion technique selection, based on the strength of each fixation type. Second, all the tests were performed under pure moment loading without any compressive preload, as the quality of the data was similar with and without the application of a compressive preload. Thus, for the scope of this study, which was a comparative evaluation of different instrumentation techniques, only pure moments were applied. In addition, the current study only addresses the immediate stability of different techniques; therefore, the long-term effect on the spinal segments needs to be further investigated. Lastly, we were unable to analyze the changes at adjacent segments secondary to instrumentation because of the lack of segmental data for other motion segments. As the UPSFSs are supposed to be less rigid and reduce the possibility of adjacent-segment degeneration, it is of great importance to explore the effects of different techniques on adjacent segments in future studies.

\section{Conclusions}

Among all these fixation techniques, BPS stabilization offers the highest stability, UPSFS shows intermediate stability, and UPS is the least stable for 2-level lumbar spinal disorders. UPSFS appears to be able to offer a less invasive choice than BPS in well-selected patients with 2-level lumbar spinal disorders.

\section{Acknowledgments}

We acknowledge Dr. Chunhui Wu for his contribution to the biochemical testing.

\section{References}

1. Aoki Y, Yamagata M, Nakajima F, Ikeda Y, Shimizu K, Yoshihara M, et al: Examining risk factors for posterior migration of fusion cages following transforaminal lumbar interbody fusion: a possible limitation of unilateral pedicle screw fixation. J Neurosurg Spine 13:381-387, 2010

2. Beaubien BP, Mehbod AA, Kallemeier PM, Lew WD, Buttermann GR, Transfeldt EE, et al: Posterior augmentation of an anterior lumbar interbody fusion: minimally invasive fixation versus pedicle screws in vitro. Spine (Phila Pa 1976) 29:E406-E412, 2004

3. Beringer WF, Mobasser JP: Unilateral pedicle screw instrumentation for minimally invasive transforaminal lumbar interbody fusion. Neurosurg Focus 20(3):E4, 2006

4. Best NM, Sasso RC: Efficacy of translaminar facet screw fixation in circumferential interbody fusions as compared to pedicle screw fixation. J Spinal Disord Tech 19:98-103, 2006

5. Choi UY, Park JY, Kim KH, Kuh SU, Chin DK, Kim KS, et al: Unilateral versus bilateral percutaneous pedicle screw fixation in minimally invasive transforaminal lumbar interbody fusion. Neurosurg Focus 35(2):E11, 2013

6. Duncan JW, Bailey RA: An analysis of fusion cage migration in unilateral and bilateral fixation with transforaminal lumbar interbody fusion. Eur Spine J 22:439-445, 2013

7. Fan CY, Hsu CC, Chao CK, Lin SC, Chao KH: Biomechani- 
cal comparisons of different posterior instrumentation constructs after two-level ALIF: a finite element study. Med Eng Phys 32:203-211, 2010

8. Feng ZZ, Cao YW, Jiang C, Jiang XX: Short-term outcome of bilateral decompression via a unilateral paramedian approach for transforaminal lumbar interbody fusion with unilateral pedicle screw fixation. Orthopedics 34:364, 2011

9. Ferrara LA, Secor JL, Jin BH, Wakefield A, Inceoglu S, Benzel EC: A biomechanical comparison of facet screw fixation and pedicle screw fixation: effects of short-term and long-term repetitive cycling. Spine (Phila Pa 1976) 28:12261234,2003

10. Goel VK, Lim TH, Gwon J, Chen JY, Winterbottom JM, Park JB, et al: Effects of rigidity of an internal fixation device. A comprehensive biomechanical investigation. Spine (Phila Pa 1976) 16 (3 Suppl):S155-S161, 1991

11. Gong Z, Chen Z, Feng Z, Cao Y, Jiang C, Jiang X: Finite element analysis of 3 posterior fixation techniques in the lumbar spine. Orthopedics 37:e441-e448, 2014

12. Harris BM, Hilibrand AS, Savas PE, Pellegrino A, Vaccaro AR, Siegler S, et al: Transforaminal lumbar interbody fusion: the effect of various instrumentation techniques on the flexibility of the lumbar spine. Spine (Phila Pa 1976) 29:E65E70, 2004

13. Hu XQ, Wu XL, Xu C, Zheng XH, Jin YL, Wu LJ, et al: A systematic review and meta-analysis of unilateral versus bilateral pedicle screw fixation in transforaminal lumbar interbody fusion. PLoS One 9:e87501, 2014

14. Jang JS, Lee SH: Clinical analysis of percutaneous facet screw fixation after anterior lumbar interbody fusion. J Neurosurg Spine 3:40-46, 2005

15. Jang JS, Lee SH: Minimally invasive transforaminal lumbar interbody fusion with ipsilateral pedicle screw and contralateral facet screw fixation. J Neurosurg Spine 3:218-223, 2005

16. Jang JS, Lee SH, Lim SR: Guide device for percutaneous placement of translaminar facet screws after anterior lumbar interbody fusion. Technical note. J Neurosurg 98 (1 Suppl):100-103, 2003

17. Kawaguchi Y, Matsui H, Tsuji H: Back muscle injury after posterior lumbar spine surgery. A histologic and enzymatic analysis. Spine (Phila Pa 1976) 21:941-944, 1996

18. Kawaguchi Y, Yabuki S, Styf J, Olmarker K, Rydevik B, Matsui $\mathrm{H}$, et al: Back muscle injury after posterior lumbar spine surgery. Topographic evaluation of intramuscular pressure and blood flow in the porcine back muscle during surgery. (Phila Pa 1976) 21:2683-2688, 1996

19. Kim SM, Lim TJ, Paterno J, Kim DH: A biomechanical comparison of supplementary posterior translaminar facet and transfacetopedicular screw fixation after anterior lumbar interbody fusion. J Neurosurg Spine 1:101-107, 2004

20. Liu F, Jiang C, Cao Y, Jiang X, Feng Z: Transforaminal lumbar interbody fusion using unilateral pedicle screw fixation plus contralateral translaminar facet screw fixation in lumbar degenerative diseases. Indian J Orthop 48:374-379, 2014
21. Magerl FP: Stabilization of the lower thoracic and lumbar spine with external skeletal fixation. Clin Orthop Relat Res (189):125-141, 1984

22. Phillips FM, Cunningham B, Carandang G, Ghanayem AJ, Voronov L, Havey RM, et al: Effect of supplemental translaminar facet screw fixation on the stability of stand-alone anterior lumbar interbody fusion cages under physiologic compressive preloads. Spine (Phila Pa 1976) 29:1731-1736, 2004

23. Sethi A, Lee S, Vaidya R: Transforaminal lumbar interbody fusion using unilateral pedicle screws and a translaminar screw. Eur Spine J 18:430-434, 2009

24. Sethi A, Muzumdar AM, Ingalhalikar A, Vaidya R: Biomechanical analysis of a novel posterior construct in a transforaminal lumbar interbody fusion model an in vitro study. Spine J 11:863-869, 2011

25. Slucky AV, Brodke DS, Bachus KN, Droge JA, Braun JT: Less invasive posterior fixation method following transforaminal lumbar interbody fusion: a biomechanical analysis. Spine J 6:78-85, 2006

26. Suk KS, Lee HM, Kim NH, Ha JW: Unilateral versus bilateral pedicle screw fixation in lumbar spinal fusion. Spine (Phila Pa 1976) 25:1843-1847, 2000

27. Xie Y, Ma H, Li H, Ding W, Zhao C, Zhang P, et al: Comparative study of unilateral and bilateral pedicle screw fixation in posterior lumbar interbody fusion. Orthopedics 35:e1517e1523, 2012

28. Zeng ZY, Zhang JQ, Song YX, Yan WF, Wu P, Tang HC, et al: Combination of percutaneous unilateral translaminar facet screw fixation and interbody fusion for treatment of lower lumbar vertebra diseases: a follow-up study. Orthop Surg 6:110-117, 2014

\section{Disclosures}

The authors report no conflict of interest concerning the materials or methods used in this study or the findings specified in this paper.

\section{Author Contributions}

Conception and design: X Jiang, Dong. Acquisition of data: T Liu, Fei, C Jiang, Li. Analysis and interpretation of data: Feng. Drafting the article: F Liu, Feng. Critically revising the article: X Jiang, F Liu, T Liu, Fei, Dong. Reviewed submitted version of manuscript: all authors. Approved the final version of the manuscript on behalf of all authors: X Jiang. Statistical analysis: Feng. Administrative/technical/material support: T Liu, Fei, C Jiang, Li. Study supervision: C Jiang.

\section{Correspondence}

Xiaoxing Jiang, Department of Orthopaedics, Zhongshan Hospital of Fudan University, 180 Fenglin Rd., Shanghai 200032, China.email: jxxspine@163.com. 